\title{
Assessment of structural condition of Libeň Bridge
}

\author{
Petr Kněž ${ }^{1, *}$, Petr Tej ${ }^{1}$, Jindřich Čech $^{1}$ and Marek Blank ${ }^{1}$ \\ ${ }^{1}$ Klokner institute, Czech Technical University in Prague, 16608 Šolínova 7, Prague, Czech Republic
}

\begin{abstract}
The paper presents diagnostic and load tests of the Inundation bridge which is part of a group of bridges called The Liben bridge group in Prague. The Libeň bridge group consists of two arched and several framed bridges spanning the Vltava river. One of the vaulted bridges consists of 5 arches and the other vaulted bridge (called Inundation bridge) consists of only one arch. Arched bridges are extraordinary structures with both technical and historical value. Since the inundation bridge has the largest arch of whole group, it was selected for testing purposes. The bridge is assembled with three-hinged arch made of concrete. The hinges are made of reinforced concrete and lead contact slabs. Detailed measurements of geometry and material properties were made on the bridge. Based on these measurements a computer model was created to verify the behavior of the structure. Both static and dynamic calculations were performed. Measurements of dynamic characteristics were made during normal operation and with hydraulic vibration exciter. This article will focus on comparing the results of dynamic calculation of the modeled structure and properties measured on real structure excited by hydraulic vibration exciter.
\end{abstract}

\section{Description of construction}

The Libeň bridge was built between 1924-1928 according to a project by architect Pavel Janak. The arched parts of the bridge were designed by engineer František Mencl. The bridge was opened for traffic on October 29, 1928 at the 10th anniversary of the Czechoslovakia in the presence of the former president Thomas G. Masaryk. The bridge arches with three hinges made of concrete are considered of an immense technical value. The arch of the inundation bridge is the largest arch of its kind in Prague. The overlap of arches on consoles are of 3 to 4.5 meters and the use of prefabricated concrete blocks for the hinges are a creative contribution of engineer Mencl. The thickness of the arch at the top hinge is $670 \mathrm{~mm}$ at the smallest arch, $830 \mathrm{~mm}$ at the largest arch, and 800 to $950 \mathrm{~mm}$ at base hinges of arches.

The arch of the Inundation bridge (Fig. 1, 2) has a span of $48 \mathrm{~m}$. The bridge carries urban traffic across an inundation area. The width of the roadway on the bridge is 14.5 meters (traffic lanes + tram line), walkways on both sides have a width of $3.25 \mathrm{~m}$. The driveway is covered with asphalt concrete, pavement surface consists of cast asphalt, and

${ }^{*}$ Corresponding author: petr.knez@,cvut.cz 
tramway lane is made of a special type of reinforced concrete panels with canals called BKV panels.

The supporting structure of the arches consist of a cast-in-place, normal strength concrete segments with embedded reinforced concrete hinges. The arches in cross section are divided into 4 segments. The segments are $4.85 \mathrm{~m}$ wide and their thickness varies between 0.9 and 1.1 meters. Each arch was designed as a three-hinged arch with one hinge at the top and two hinges positioned on cantilevers roughly 3 meters of a distance from pillars.

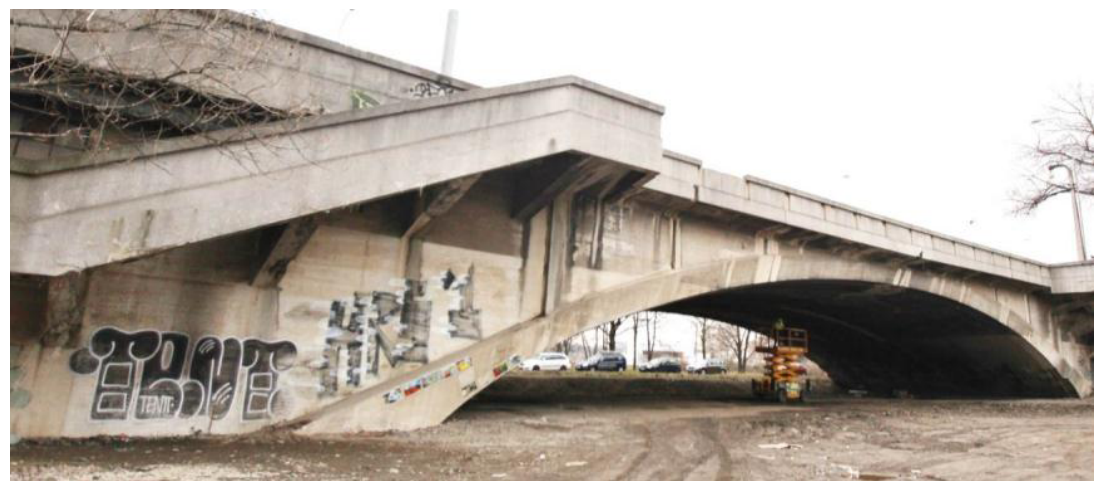

Fig. 1. The construction of Inundation Bridge.

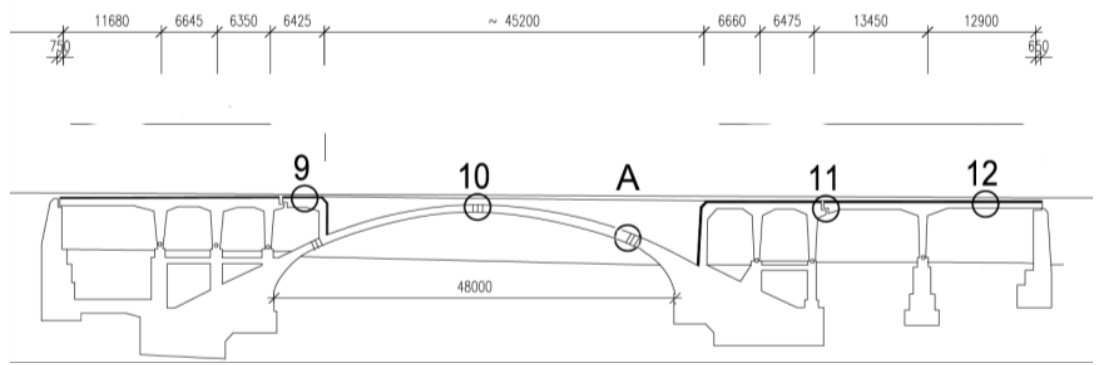

Fig. 2. Longitudinal section of Inundation Bridge.

\section{Diagnostics and load tests}

\subsection{Diagnostics}

Within the project, control tests of the concrete specimens taken from the bridge arch were carried out. To determine the mechanical properties and a frost resistance, tests were performed on these specimens.

The following statements were made based on the results obtained from the tests:

- The cement paste has been leached for an extended period of time. Concrete degraded due to the alternation of freezing and thawing and due to the technology of casting used during construction. The technology of casting of concrete induced very high inhomogeneity manifested as caverns, macropores and gaps in the concrete structure. The inhomogeneity due to casting is also linked to high variability of properties. Completely disintegrated regions with strength between 0 and $5 \mathrm{MPa}$ were found in the 
samples. These sections could not be mechanically tested; thus, they were not included in the evaluation of the strength by conventional methods according to standards.

- when evaluating the concrete samples according to EN 13791, the characteristic strength of concrete for the group of samples was determined with regard to the presence of gaps, caverns and overall visual assessment. The lowest characteristic strength in the concrete mass of the arch was determined as $21.9 \mathrm{MPa}$ therefore the corresponding strength class C 20/25.

- The average compressive modulus of elasticity of all examined arches was set at 27.3 $\mathrm{GPa}$. This value corresponds to strength class C 16/20.

- Embedded concrete hinges were found to be stronger than the rest of the structure, with a corresponding strength class C $35 / 45$.

-Water absorption of the examined concrete structure was found to be of a relatively low value, ranging from $2.5 \%$ to $6.1 \%$. Such low percentage should indicate sufficient frost resistance. However, during the frost resistance testing the opposite was revealed. The test was carried out on 19 concrete samples according to CSN 731322. Out of the 19 specimens, 4 were completely disintegrated after 25 freeze-thaw cycles. After additional 50 freezing cycles, another 7 samples were completely disintegrated. Therefore after 75 freeze-thaw cycles $58 \%$ of the concrete samples disintegrated. The concrete in its current state is not resistant to frost.

\subsection{Load tests}

\subsubsection{Static load test}

The load of the static load test was represented by four trucks Iveco Trakker $8 \times 4$ weighing $25 \mathrm{t}$ symmetrically placed at the top of arch (load condition 1 ) or three trucks Iveco Trakker $6 \times 4$ weighing 25 t placed asymmetrically on one side of the arch (load condition 2 and 3 ).

Tested bridge complied the static load test in terms of permanent deformation to conditions of CSN 736209 "Load testing of bridges" in 1996.

The measured deflection was $0.76 \mathrm{~mm}$ at the top hinge in the vertical direction for the first load condition.

\subsubsection{Dynamic load test}

Dynamic load test was executed by a hydraulic vibration exciter type INSET in Mode for harmonic excitation (frequency sweep) in the frequency range of 1-20 Hz. Two locations of the exciter were proposed for the dynamic load test. The first location (B1) was in one third of the span of the arch above the first transverse arch at $2 / 3$ of its width. The second location (B2) was in the middle of the span over the second transverse in the middle of the arch. In the first position, the excitation was induced in the vertical and horizontal direction. For the second position, the excitation was induced only vertically. The measured eigenfrequencies are shown in Table 1 . The values in parentheses were not accepted. 
Response of the structure was measured using sensors of speed of oscillation. First group of sensors was fastened to the lower surface of the arch. Second group of sensors was placed on the roadway approximately in the same position as the first group, but on the upper surface of the arch. The sensors were placed on all four arches of the arch. Sensors were always in the place of the hinges and in the distance corresponding to approximately $1 / 10$ of the span. The eigenfrequencies, the corresponding mode shapes (Fig. 3, 4) and the attenuation of structure were examined.

The load tests revealed that the structure is eligible for operation even in its current state.

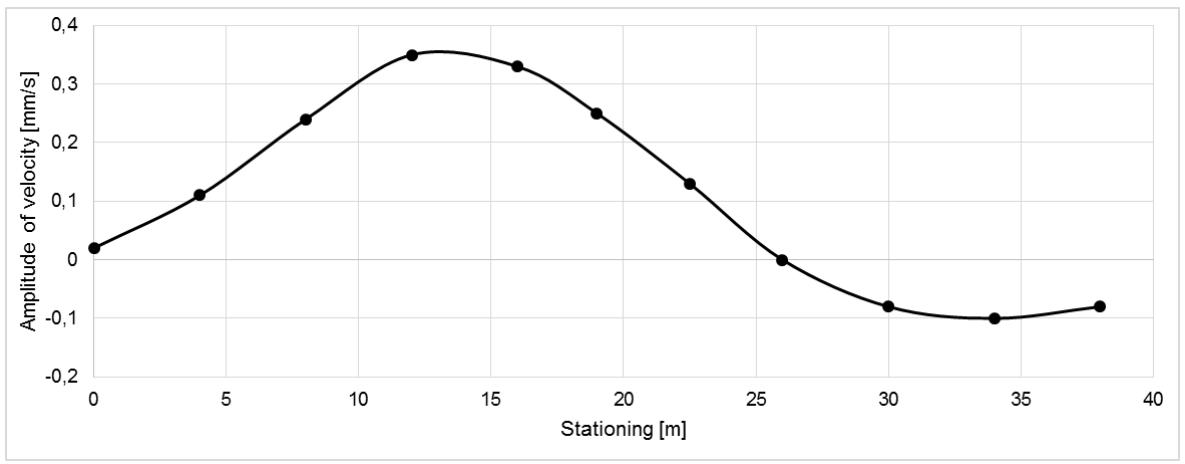

Fig. 3. Mode shapes during excitation in the vertical direction in the first position, frequency of forced vibration $4.63 \mathrm{~Hz}$.

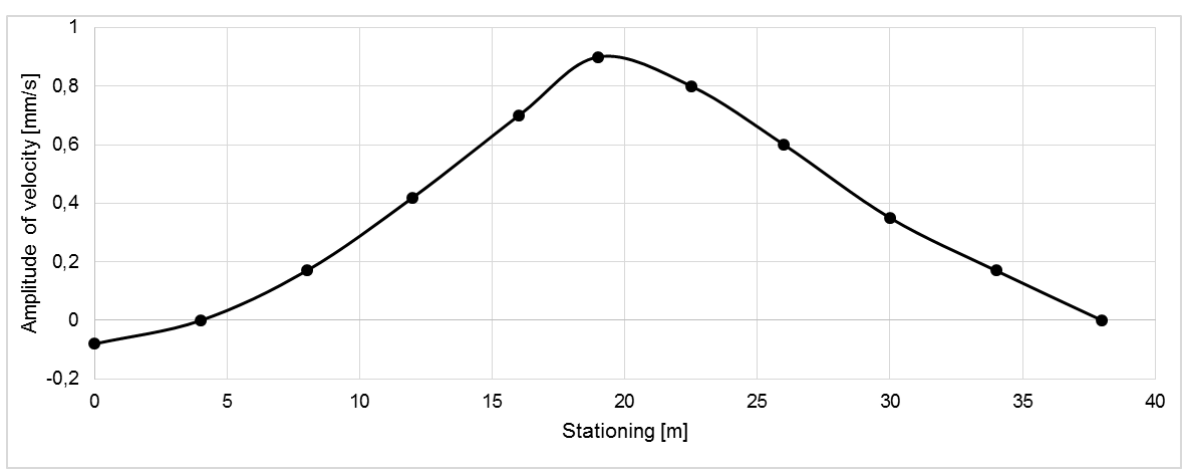

Fig. 4. Mode shapes during excitation in the vertical direction in the second position, frequency of forced vibration $4.98 \mathrm{~Hz}$. 
Table 1. Measured eigenfrequencies for vertical (V) and horizontal (H) direction.

\begin{tabular}{|c|c|c|c|}
\hline \multirow{2}{*}{ Mode shape } & \multicolumn{3}{|c|}{ Frequency [Hz] } \\
\cline { 2 - 4 } & Exciter B1 (V) & Exciter B1 (H) & Exciter B2 \\
\hline 1 & 4.63 & 5.00 & $(4.63)$ \\
\hline 2 & $(4.98)$ & 6.73 & 4.98 \\
\hline 3 & $(7.03)$ & 7.40 & $(7.03)$ \\
\hline 4 & - & 7.76 & 8.03 \\
\hline 5 & $(9.08)$ & - & 9.08 \\
\hline 6 & $(10.30)$ & - & 10.30 \\
\hline 7 & $(12.20)$ & - & $(12.20)$ \\
\hline 8 & $(13.40)$ & - & 13.40 \\
\hline 9 & $(16.60)$ & - & $(16.60)$ \\
\hline
\end{tabular}

\section{Numerical modeling}

A model of a three-hinged arch bridge KL6 was created in Scia Engineer 15 as a slab-wall construction with serrated top hinge and sloping base hinges. The modeled shape of the bridge was based on the measured geometry and historical documents.

Stiffness of the model was adjusted for the deformation to match the deflection of the structure determined in a static load test (Fig. 5). Maximum deflection of the structure during the static load test was measured in a top hinge and had a value of $0.76 \mathrm{~mm}$.

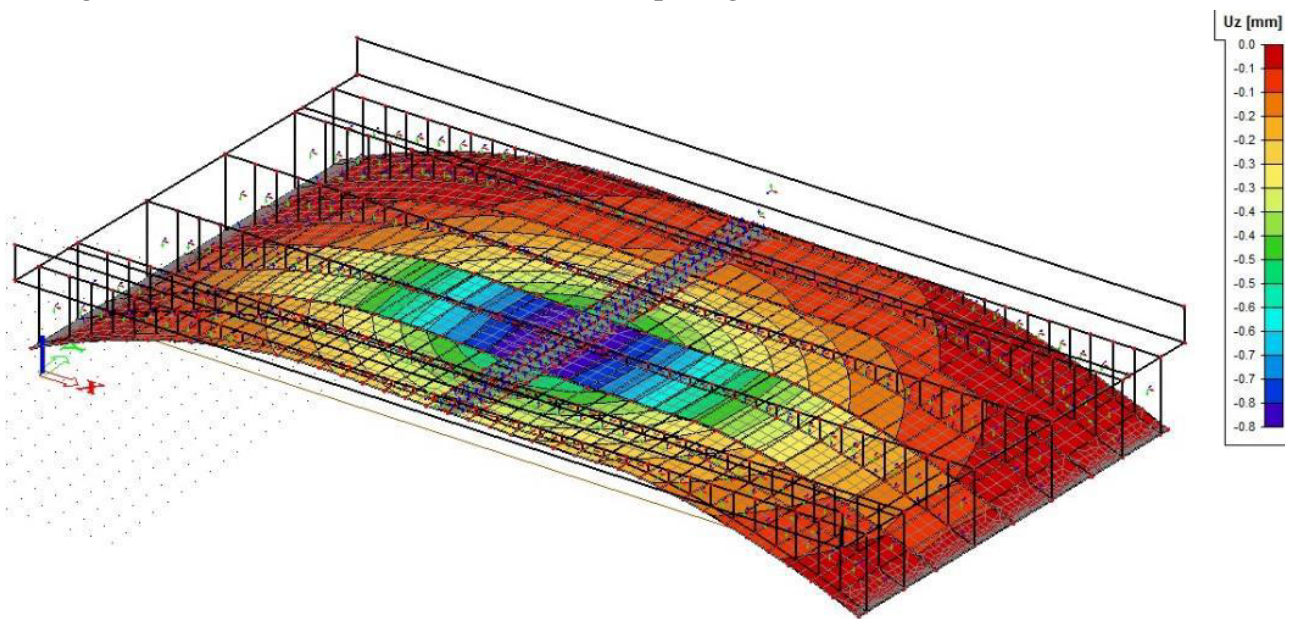

Fig. 5. Displacement in the vertical direction with modified stiffness.

Material characteristics of the concrete arches were taken from the diagnostics. Classes $\mathrm{C} 16 / 20$ and $\mathrm{C} 20 / 25$ of concrete were used. Material properties for embankment, roadway and wall bearing sidewalk bracket were altered to obtain adequate density and stiffness. 
The resulting modulus of elasticity: $E_{\text {embank }}=7.5 \mathrm{GPa}, E_{\text {roadway }}=10 \mathrm{GPa} E_{\text {wall }}=27 \mathrm{GPa}$. Rigidity of the central hinge was set at $150 \mathrm{MNm} / \mathrm{rad} / \mathrm{m}$.

Eigenfrequencies and mode shapes were calculated using the modal analysis (Fig. 6, 7).

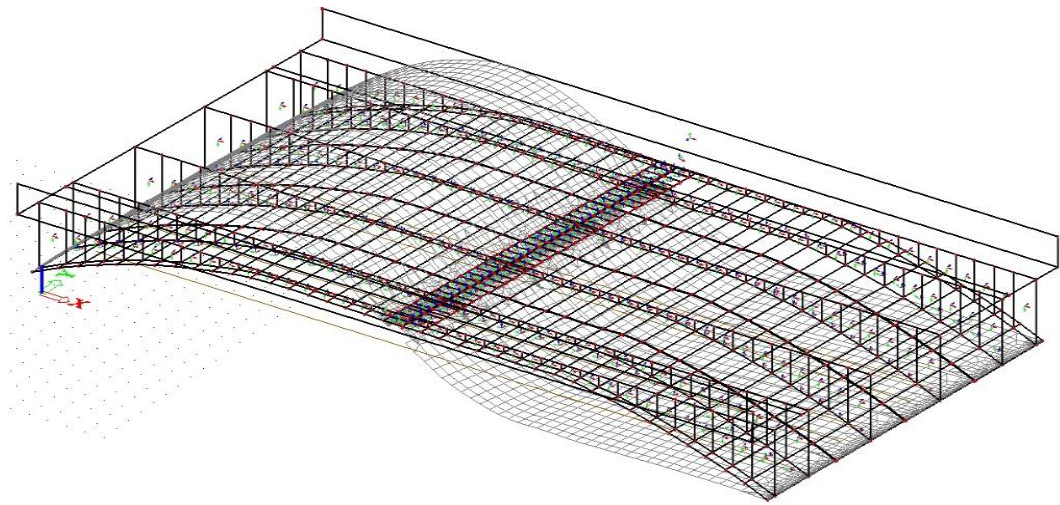

Fig. 6. Mode shape, frequency $4.97 \mathrm{~Hz}$.

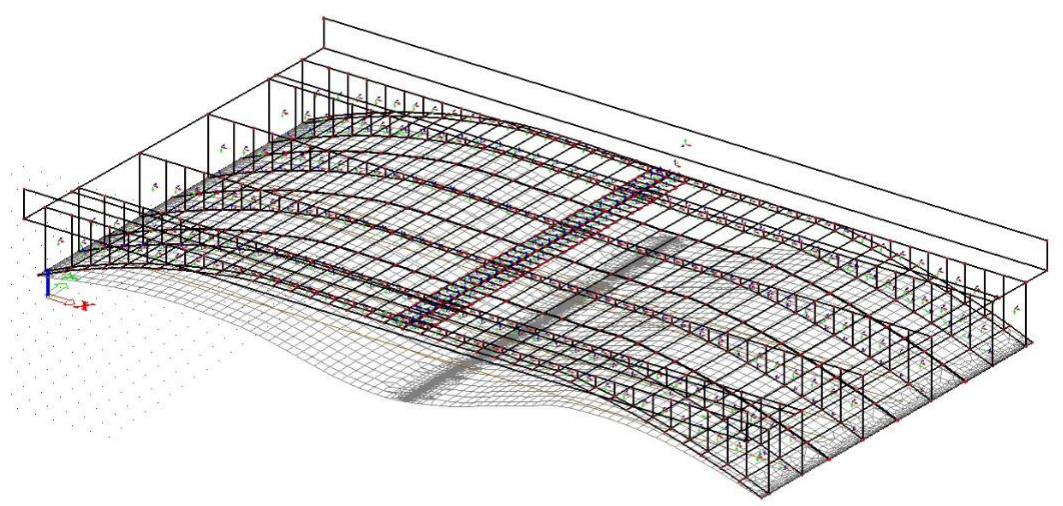

Fig. 7. Mode shape, frequency $5.78 \mathrm{~Hz}$.

\section{Conclusion}

Static and dynamic load tests showed that the structure of the inundation bridge in its current state can handle the required load transfer induced by traffic.

The stiffness of the numerical model was adjusted according to results from the static load test. After the adjustment of the model, a relatively good agreement of the results was found for the first and fourth eigenfrequency. The differences between the other eigenfrequencies and mode shapes was most likely caused by the degradation of concrete at some parts of arches and the due to discrepancies between the modeled and real nature of the connection between arches. In the SCIA model the connection between arches was provided only by top slab of roadway. The model depicts an arch in perfect condition and made of a homogeneous concrete, whereas the real structure is at least partly degraded. Comparison between calculation and measurement with mode shape assignment is shown in Table 2. 
Table 2. Mode shapes and eigenfrequencies assignment.

\begin{tabular}{|c|c|c|}
\hline Mode shape & $\begin{array}{c}\text { Dynamic calculation } \\
{[\mathbf{H z}]}\end{array}$ & $\begin{array}{c}\text { Modal analysis } \\
{[\mathbf{H z}]}\end{array}$ \\
\hline 1 & 4.97 & $4.63(\mathrm{~B} 1, \mathrm{~V})$ \\
\hline 2 & 5.78 & $4.98(\mathrm{~B} 2)$ \\
\hline 3 & 6.29 & $5.00(\mathrm{~B} 1, \mathrm{H})$ \\
\hline 4 & 6.71 & $6.73(\mathrm{~B} 1, \mathrm{H})$ \\
\hline 5 & 8.72 & $8.03(\mathrm{~B} 2)$ \\
\hline 6 & 11.39 & $9.08(\mathrm{~B} 2)$ \\
\hline
\end{tabular}

This project is supported by grant GAČR 15-05791S

\section{References}

1. Z. Bittnar, J. Šejnoha,: Numerical Methods in Sructural Mechanics, ASCE Press, (1996)

2. Dynamics of Bridges, Vol. 5, Proceedings of the $28^{\text {th }}$ IMAC, A Conference on Structural Dynamics (2010)

3. Czech standard ČSN 73 6209, Load testing of bridges (1996)

4. Czech standard ČSN 736201 - Desing of bridge structures

5. Czech standard CSN 736203 - Bridge loads

6. Czech standard ČSN EN 1991-2 - Traffic loads on bridges“"

7. Czech standard ČSN EN 1992-2 - Concrete bridges - Design and detailing rules

8. P. Tej, P. Kněž, J. Kolísko, P. Bouška: Libeň Bridge, Prague 7 A 8. innundation bridge $X-656$ - arch KL 6 and subsequent frame constructions, Expert report (only in Czech), Klokner institute, (2016)

9. P. Tej, J. Kolísko, P. Bouška, V. Vacek: Libeň bridge, Prague 7 A 8, N. A. 999984. Analysis and assessment of the current technical condition of motifs and possibilities of repairs or construction of a new bridge based on submitted diagnostic examinations and project documentation, Expert report (only in Czech), Klokner institute, (2015)

10. M. Krejcar, P. Chlopčíková, L. Záleský: Static load test, report (only in Czech), Inset, (2016)

11. M. Krejcar, J. Machač, J. Formánek: Dynamic load test of bridge, report (only in Czech), Inset, (2016) 